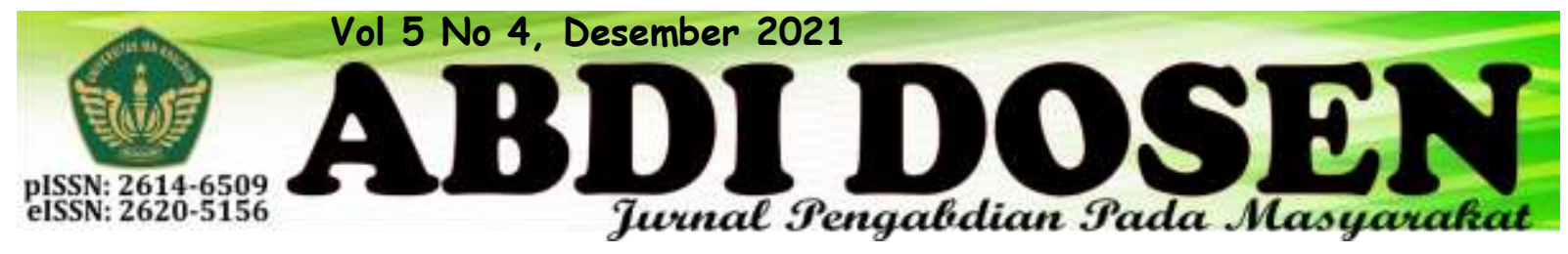

\title{
PENULISAN SYSTEMATIC LITERATURE REVIEW (SLR) PADA JURNAL TERINDEKS
}

\author{
Anita Dewi Ekawati ${ }^{1}$, Sri Kusuma Ningsih ${ }^{2}$, Yati Suwartini ${ }^{3}$, Elda C. Wenno ${ }^{4}$ \\ anita.dewieka@uhamka.ac.id 1 \\ Fakultas Keguruan dan Ilmu Pendidikan, Universitas Muhammadiyah Prof. DR. HAMKA (UHAMKA)
}

\begin{abstract}
ABSTRAK
Penulisan artikel dengan menggunakan metode Systematic Literature Review (SLR) banyak dijumpai pada jurnal terindeks. Hal ini berarti peluang untuk menerbitkan jurnal bertema SLR pada jurnal bereputasi sangat besar. Namun belum banyak calon penulis memahami cara penulisan SLR. Kegiatan Pengabdian Kepada Masyarakat (PKM) berjudul "Penulisan Systematic Literature Review (SLR) Pada Jurnal Terindeks" yang dilaksanakan melaui daring dengan menggunakan media zoom meeting pada 8 Juni 2021 diharapkan dapat membantu penulis artikel dalam memahami penulisan sehingga memudahkan penulis dalam mempublikasikan penulisannya pada jurnal terindeks.
\end{abstract}

\section{Kata Kunci : Systematic Literature Review (SLR), Jurnal Terindeks, Publikasi}

\section{PENDAHULUAN}

Pada jurnal bereputasi artikel Systematic Literature Review (SLR) banyak ditemui. Hal itu berarti penulisan dengan menggunakan metode SLR memiliki daya tarik bagi penerbit dan pembaca jurnal. Sehingga penulisan menggunakan SLR menjadi topik yang menarik untuk dibahas.

Belum banyak penulis artikel yang memiliki pemahaman yang mendalam mengenai metode ini. Disisi lain jika dilihat secara keseluruhan dari segi pembaca, penulisan SLR ini sangat membantu pemahaman mengenai isi dari jurnal yang dibahas dalam SLR. Dalam satu artikel SLR, pembaca dapat dengan mudah menyimpulkan isi dari berbagai jurnal dengan dibantu tulisan dalam artikel. Oleh karena itu, diperlukan kemahiran penulis artikel dalam mengolah kalimat agar kandungan jurnal yang dibahas tetap utuh.

Xia et al. (2018) dalam Tan, Le, \& Xuan (2020) mendeskripsikan metode SLR dalam bagan sebagai berikut: 


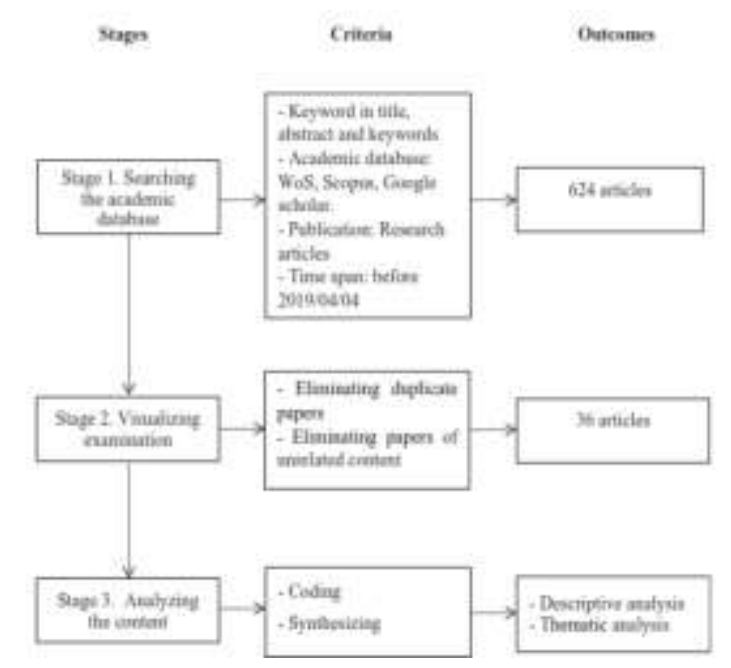

Dari bagan tersebut dapat disimpulkan bahwa SLR terdiri dari tiga tahap, yaitu:

1. Mencari database berdasarkan pada kata kunci dalam judul abstrak, mencari pada database akademik (WoS, Scopus, Google schoolar, dan lain database lainnya), mencari publikasi berdasarkan penelitian artikel dan rentang waktu: sebelumnya.

2. Memeriksa kembali artikel penelitian yang ditemukan dengan menghilangkan dokumen yang duplikat, dan menghilangkan artikel penelitian yang tidak terkait.

3. Menganalisis isi dari artikel penelitian dengan mengkoding dan mensintesa.

Penggunaan tinjauan SLR bertujuan untuk mengatasi masalah ini "dengan mengidentifikasi, mengevaluasi secara kritis, dan mengintegrasikan temuan dari semua studi individu yang relevan dan berkualitas tinggi yang membahas satu atau lebih pertanyaan penelitian" (Siddaway, n.d., p. 1 dalam Iskhakova, Hoffmann, \& Hilbert, 2017). Sedangkan Anderson \& Collins, 2014; Arksey \& O’Malley, 2005 dalam Soaita, Serin, \& Preece (2019)(Soaita et al., 2019) menyatakan bahwa SLR memiliki tujuan untuk memetakan literatur yang luas dibingkai oleh tema yang luas dan melaporkannya spasial, temporal, tren konseptual dan tematik dengan memperhatikan langkahlangkah dalam menginformasikan ulasan yang kuat.

\section{Keadaan Geografis}

Pengabdian ini dilakukan secara daring dengan menggunakan media zoom meeting karena adanya pembatasan wilayah selama pandemic Covid-19. Langkah untuk mendapatkan tautan pertama calon peserta mendaftar melalui link yang disediakan oleh panitia, setelah mendaftar peserta diberikan tautan untuk masuk ke zoom meeting.

\section{Kondisi Peserta}

Berdasarkan analisis pada link pendaftaran peserta, peserta mengikuti webinar mengenai SLR ini agar memiliki pemahaman yang baik sehingga peserta dapat mengirimkan artikel mereka pada jurnal bereputasi. Peserta berharap mereka tidak kesulitan dalam memahami konsep SLR sehingga artikel yang mereka buat layak terbit pada jurnal terindeks. Dengan demikian, makin banyak penulis yang dapat membahas SLR dalam berbagai jurnal. 


\section{METODE PEGABDIAN}

Tahap 1: Persiapan (Survei dan Wawancara dengan beberapa orang calon peseta)

Tim PKM mengadakan survei dan wawancara langsung dengan calon peserta membahas tentang SLR.

Tahap 2: Rapat Koordinasi dengan Tim PKM

Tim PKM melaksanakan rapat koordinasi dalam hal pemantapan kegiatan pengabdian. Beberapa hal yang akan dibahas pada rapat ini di antaranya adalah materi pelatihan dan pengaturan agenda kegiatan selama pelatihan berlangsung.

Tahap 3: $\quad$ Pengolahan Informasi
Tim PKM memilih narasumber untuk menyampaikan materi mengenai SLR.

Tahap 4: $\quad$ Tim PKM membuat link pendaftaran dan tautan zoom meeting.

Tahap 5: Pelaksanaan Program

a) Waktu dan Tempat Kegiatan

Kegiatan pelatihan dilaksanakan pada tanggal 8 Juni 2021 melalui zoom meeting.

b) Peserta Kegiatan

Pelatihan ini akan dihadiri oleh 15 peserta.

c) Kegiatan Pelatihan

Acara ini dibuka dengan materi oleh narasumber dan tanya jawab oleh peserta

Tahap 6: $\quad$ Pembuatan Laporan

\section{Jadwal Kegiatan}

\begin{tabular}{|c|c|c|c|c|c|c|c|c|c|c|c|c|c|}
\hline \multirow{3}{*}{ No } & \multirow{3}{*}{ Jenis Kegiatan } & \multicolumn{12}{|c|}{ Waktu Pelaksanaan } \\
\hline & & \multicolumn{4}{|c|}{ April 2021} & \multicolumn{4}{|c|}{ Mei 2021} & \multicolumn{4}{|c|}{ Juni 2021} \\
\hline & & 1 & 2 & 3 & 4 & 5 & 6 & 7 & 8 & 9 & 10 & 11 & 12 \\
\hline 1 & $\begin{array}{l}\text { Persiapan (Survei dan Wawancara dengan } \\
\text { Mitra) }\end{array}$ & & & & & & & & & & & & \\
\hline 2 & $\begin{array}{l}\text { Koordinasi dengan Tim PKM (Pembagian } \\
\text { Tugas) }\end{array}$ & & & & & & & & & & & & \\
\hline 3 & Pengolahan Informasi & & & & & & & & & & & & \\
\hline 4 & $\begin{array}{l}\text { Tim PKM membuat link pendaftaran dan } \\
\text { tautan zoom meeting. }\end{array}$ & & & & & & & & & & & & \\
\hline 5 & Pelaksanaan program & & & & & & & & & & & & \\
\hline 6 & Pembuatan Laporan & & & & & & & & & & & & \\
\hline
\end{tabular}

\section{REALISASI PROGRAM}

Pelaksanaan pengabdian kepada masyarakat dilaksanakan secara daring melui tautan zoom meeting yang sudah disediakan panitia Webinar.

Kegiatan pengabdian kepada masyarakat dimulai dengan registrasi peserta pada tanggal 1-5 Juni 2021 melalui tautan yang diberikan. Setelah melakukan pendaftaran peserta diberikan link melalui e-mail.

Peserta yang hadir sebanyak 15 orang. Pelaksanaan pengabdian dimulai pada pukul 13.00 dengan sambutan oleh ketua panitia PKM. Acara dilanjutkan dengan materi oleh narasumber, bapak 
Herri Mulyono, Ph.D. pada pukul 13.15 dan

dilanjutkan dengan sesi tanya jawab.

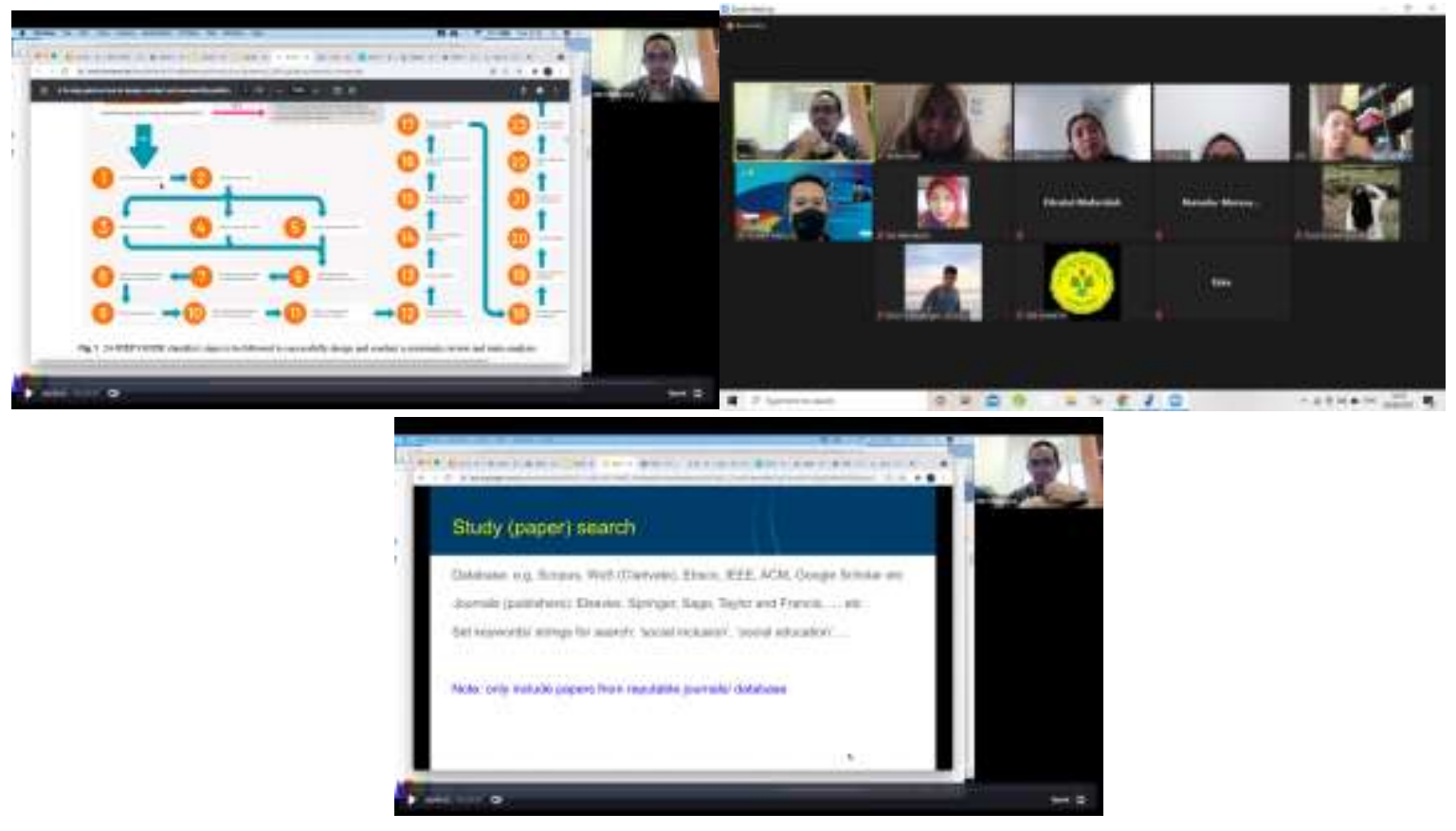

\section{KESIMPULAN}

Kemahiran dalam penulisan SLR dapat memberikan peluang dalam mempublikasikan artikel dalam jurnal bereputasi. Berdasarkan hasil evaluasi

\section{DAFTAR PUSTAKA}

Iskhakova, L., Hoffmann, S., \& Hilbert, A. (2017). Alumni Loyalty: Systematic Literature Review. Journal of Nonprofit and Public Sector Marketing, 29(3), 274-316. https://doi.org/10.1080/10495142.20 17.1326352

Soaita, A. M., Serin, B., \& Preece, J. (2019). A methodological quest for systematic literature mapping. International Journal of Housing pelaksanaan kegiatan pengabdian kepada masyarakat, saran yang diberikan:

Perlu adanya pelatihan lebih lanjut dalam menulis SLR.

Policy, https://doi.org/10.1080/19491247.20 19.1649040

Tan, L. P., Le, A. N. H., \& Xuan, L. P. (2020). A Systematic Literature Review on Social Entrepreneurial Intention. Journal of Social Entrepreneurship, 11(3), 241-256. https://doi.org/10.1080/19420676.20 19.1640770 